\title{
Practice of Knowledge Management for Retention of Intellectual Knowledge in Small and Medium Enterprises
}

\author{
Ashraf Khaled Magableh ${ }^{1 *}$ \\ ${ }^{1}$ University of Technology Sydney, Australia
}

\section{OPEN ACCESS}

Citation: Magableh A.K. (2018) Practice of Knowledge

Management for Retention of Intellectual Knowledge in Small and Medium Enterprises.Open Science Journal 3(2)

Received: $3^{\text {rd }}$ October 2017

Accepted: $21^{\text {st }}$ January 2018

Published: $21^{\text {st }}$ May 2018

Copyright: (C) 2018 This is an open access article under the terms of the Creative Commons Attribution License, which permits unrestricted use, distribution, and reproduction in any medium, provided the original author and source are credited.

Funding: The author(s) received no specific funding for this work

Competing Interests: The author have declared that no competing interests exists.
*Corresponding author: Ashraf Khaled Magableh: ashrafmagableh@yahoo.com

\section{Abstract:}

The research will explore and identify the components of knowledge management including knowledge components, knowledge management process, Information technology (IT) and organization / corporate culture eliciting and depicting tacit and explicit knowledge. Further, the research will include the both qualitative and quantitative research implementing ethnographic methodology and online survey and open-ended interview with relevant intellectuals. Additionally, knowledge management is considered as value added to data, personnel perception, and fundamental of knowledge and the knowledge management process will consist of three distinct sub-processes i.e. create, disseminate, and incorporate. Finally, the report will focus on four distinct divisions of knowledge sub-processes for example knowledge creation and acquisition, knowledge organization and retention, knowledge dissemination, and knowledge utilization to improve the effectiveness and efficiency of small and medium enterprises.

Keywords: Knowledge Management, Knowledge Components, Knowledge Management Process, Corporate Culture, Information Collection 


\section{Introduction}

The research paper focuses on knowledge components, knowledge management process, Information Technology, organization / corporate culture and explores the Quantitative Research Methodology as a tool for the research. Further, the report discusses the Research Methodology, Information collection, structure and sequence of questions.

The concept of knowledge management evolved over the last five decades. In recent era, with the evolution of Information Technology, it gained momentum and found an objective to improve the management of knowledge leading into wisdom. Further, researchers like Chua 2004, Hoegl \& Schulze 2005, Liao 2003 etc contributed methodology to measure the knowledge and the impact upon the human life. According to Lee and Kim (2001), knowledge management includes four basic components such as knowledge components, knowledge management process, information technology (IT), and organization / corporate culture.

- Knowledge Components

- Knowledge management process

- Information technology (IT)

- Organization / corporate culture.

\section{Knowledge Components:}

Apparently, knowledge has been divided into two components i.e. theoretical and practical. Theoretical components are associated with definitions and principles. Further, it integrates interpretations and relations among data, information, knowledge and wisdom (Kim and Lee 2003). Earl (1994) and Alter (1993) illustrate that data is a combination of facts, images and/or sounds, however, it should be analysed to evaluate the knowledge and wisdom. Further, information is considered as value added to data, personnel perception, and fundamental of knowledge. Furthermore, knowledge consists of Personal perception, output of information, organizational resources, and combination of personal perception and output of information. Additionally, tacit knowledge is implicit, whereas, explicit knowledge consists of formal models, rules and procedures.

\section{Knowledge management process:}

The prominent researchers of knowledge management process Nonaka and Takeuchi (1995) categorise knowledge management process into three distinct sub-processes: create, disseminate, and incorporate. Further, the literature proposes four distinct division of knowledge sub-processes for example knowledge creation and acquisition, knowledge organization and retention, knowledge dissemination, and knowledge utilization. The acquired knowledge should be examined, verified and validated against its authenticity before considering it as 
knowledge and sharing it. Additionally, knowledge worker needs to codify the tacit knowledge, to the extent possible, to share effectively. The process of dissemination and utilization generate value to the knowledge (Demarest 1997).

\section{Information Technology:}

Information technology enhanced and became the backbone of Knowledge Management and is the key enabler for knowledge management practices. According to Alavi and Leidner (2001), KMS is as an IT based system developed to support the organization knowledge management behaviour. Further Liao (2003) discusses knowledge management technologies and applications into seven categories: (i) knowledge management framework, (ii) knowledge-based system (KBS), (iii) data mining (DM), (iv) information and communication technology (ICT), (v) artificial intelligence (Al)/expert system (ES), (vi) database technology (DT), and (vii) modelling.

\section{Organization / Corporate Culture:}

The Organization/corporate culture play an important role in signifying the knowledge management practices in the organization. Further, the culture encourages their employee to share the ideas, experiences, and viewpoints on any associated topic. Additionally, an openness and flexible should be developed in the organization to accumulate the tacit and explicit knowledge. Sveiby and Simons (2002) contribute that a collaborative atmosphere consisting of organizational culture, supervisor, employee attitude, and knowledge worker determines knowledge creation and knowledge transfer process.

\section{The Research Method}

For the current research, Quantitative Survey is proposed as it provides an inexpensive method to gather information from large number of potential respondents. Moreover, the confidentiality and privacy of the respondent is well protected. Questionnaire survey is a fast and powerful versatile evaluation tool. The process initiates with an understanding of the capabilities of a questionnaire and effectiveness in the research. Questionnaires are like scientific experiment (Kasunic, 2005). A hypothesis is formed and is accepted or rejected depending upon the result of the research. It permits the gathering of closed ended and open ended questions.

The research questions will be based upon the behavior of knowledge workers in Information Technology Software Development. Moreover, a Pilot test will be done to finalize the actual question for the actual survey. The target respondent will be Knowledge workers and IT Professionals. A set of close-ended questions will be framed and will require a frequency based answer from the respondent. The close ended questions will enable respondent to decide quickly and 
effectively. The following process will be followed to design the questionnaire, gather the information and finally analyze the data. The research study will require two years and another one year to evaluate and analyze the result of the Pilot study.

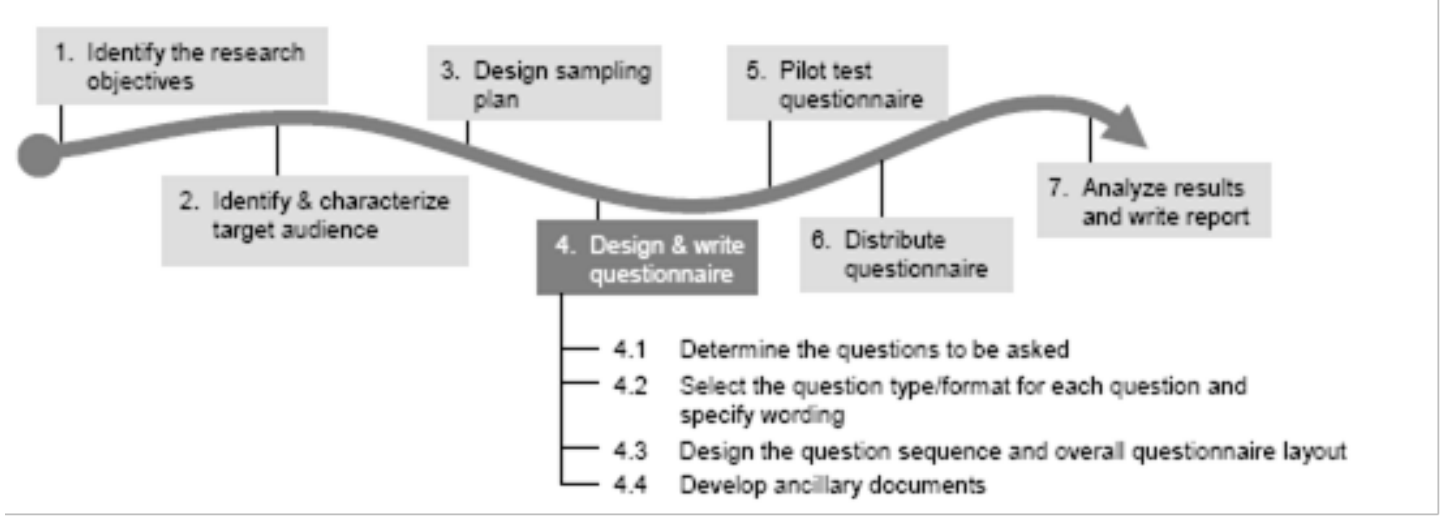

(Source: Adapted from Kasunic, M. 2005, P. 33)

\title{
Research Methodology
}

\author{
-Survey type \\ -Quantitative \\ - Target Audience \\ -Suburban Population \\ -Question Type \\ -Close-ended type \\ - Structure and Sequence \\ -Introduction and Instructions \\ -Questionnaire Body \\ - Time Frame \\ -Survey 6 Months \\ -Evaluation and Analysis 1 Months \\ Information collection
}

The best way of information collection is to conduct web based online survey focusing on Knowledge workers and IT Professionals. The web based survey provides fast response rate and incur less cost, besides, respondent can answer honestly because identity is not disclosed. Moreover, the processing of data is easier and has got dynamic error detecting facility. The user can tick only at the appropriate place and cannot select two options. The survey questionnaire will be sent to the Target audience by mail. The survey is divided into two sections for clarity and data encoding. The first section deals with the demographic and background information of the respondent. The second section deals with the actual questions related to their response and suggestions. Close ended questions are designed to collect the information as it will be easier for the respondent to come out with the answer quickly, easily and effectively.

Additionally, the survey will provide instructions and guidelines to the respondent. A request of survey will be mailed to the people randomly selected to 
contribute in order to assess and analyse. In fact, this will assist us the determining the solution to the society to avoid the epidemics and medical issues in the Society.

\section{Target Audience}

The target respondent for this questionnaire is the people practicing Knowledge Management and IT Professionals. The survey will target the people who have at least three years of IT Experience or have Post graduate degree in IT or associated with knowledge management for the past three years. It will provide an accurate data and the processing of data will provide accurate and effective result.

\section{Question Type}

There will be self-administered questionnaire and the questions are of closedended type, rather than the open-ended type. The questionnaire requires a frequency based answer from the respondent. The questions are close ended with ordered response and it will enable respondent to decide quickly and effectively.

\section{Data Encoding}

This questionnaire is involved in only close-ended questions and hence, there is no requirement of response encoding. The response will be converted to numbers and can be assessed quickly. The analysis can be done after the respondents' answers will be collected.

\section{Specific Wording of the Questions}

The language of the questionnaire will be Arabic and the wording of the questions will be very simple and grammar, tense and question construction is taken into consideration. There will be no use of technical words which will be difficult to understand.

\section{Structure and Sequence of Questions}

\section{Introduction and Instructions}

There will be one introductory page which will contain a brief explanation of the purpose of the survey. The introduction will also serve as a reference point. If the respondent wants to understand any of the questions, then he can contact the 
surveyor. This part of the questionnaire will describe the reason for doing the research and ensure that the respondents are fully informed about the nondisclosure policy. The introduction will be followed by a set of instructions that need to be read carefully and followed before proceeding to answer the actual questionnaire.

\section{The Questionnaire Body}

The questionnaire will comprise of close-ended questions and the sequence of questions is maintained. The questions are sequenced in a way that each succeeding question has link with the previous one. The surveyor intends that the respondents read and understood the research topic and the purpose of conducting the survey. The respondent should think honestly regarding the frequency before answering the question.

\section{Research Plan}

The research plan defines a framework to analyze the principles and care will be taken to lead ultimate and consistent expectation and delivery of the research. The resources will be adequately projected. The milestones and deadlines will be clearly articulated and will be achieved, and time will be provided for periodic reviews and audit of the research to improve the quality of the report. Finally, it will be ensured that the report will be accomplished and delivered on time with high level of quality successful achievement of Research paper's objectives.

Appendix 1 (Schedule)
\begin{tabular}{|l|l|l|}
\hline \multicolumn{1}{|c|}{ S. No. } & \multicolumn{1}{|c|}{ Activities } & \multicolumn{1}{|c|}{ Duration } \\
\hline 1. & Literature Review & 6 months \\
\hline 2. & Designing of Questionnaire & 3 months \\
\hline 3. & Distributing the Questionnaire & 3 months \\
\hline 4. & Gathering responses & 6 months \\
\hline 5. & Analyse results & 6 months \\
\hline 6. & Review & 2 months \\
\hline 7. & Write Research Report & 10 months \\
\hline
\end{tabular}

\section{References:}

Alavi, M. and Leidner, D.E. 2001, 'Review: knowledge management and knowledge management systems: conceptual foundations and research issues', MIS Quarterly, Vol. 25, pp. 107-136.

Alter, S. 1996, 'Information Systems, A management perspective', Menlo Park, CA: BenjaminCummings Publishing Company.

Chua, A. 2004, 'Knowledge management system architecture: a bridge between KM consultants and technologists', International Journal of Information Management, Vol. 24, pp. 87-98.

Demarest, M. 1997, 'Understanding Knowledge Management', Long Range Planning, Vol. 30, pp. 374384. 
Du Plessisa, M. and Boonb, J.A. 2004, 'Knowledge management in eBusiness and customer relationship management: South African case study findings', International Journal of Information Management, Vol. 24, pp. 73-86

Earl, M.J. 1994, "Knowledge as strategy: reflections on Skandia International and Shorko Films," in Strategic Information Systems: A European Perspective, eds.: C. Ciborra, T. Jelassi, New York: Wiley, pp. 53-69.

Hanley, S. \& Malafsky, G. 2003, 'A guide for measuring the value of KM investments In C. W. Holsapple (Ed.)', Handbook of Knowledge Management, Vol. 2, pp. 369-390

Hoegl, M. and Schulze, A. 2005, 'How to Support Knowledge Creation in New Product Development: An Investigation of Knowledge Management Methods', European Management Journal Vol. 23, No. 3, pp. 263-273.

Kasunic, M. (2005), 'Designing an effective survey', Carnegie Mellon, Software Engineering Institute

Kim, Y.G., Yu, S.H. and Lee, J.H. 2003, 'Knowledge strategy planning: methodology and case', Expert Systems with Applications, Vol. 24, pp. 295-307.

Lee, J.H. and Kim, Y.G. 2001, 'A stage model of organizational knowledge management: a latent content analysis', Expert Systems with Applications, Vol. 20, pp. 299-311.

Liao, S.H. 2003, 'Knowledge management technologies and applications literature review from 1995 to 2002', Expert Systems with Applications, Vol. 25, pp. 155-164.

Nonaka, I. and Takeuchi, H. 1995, The Knowledge-creating Company, New York: Oxford University Press, Oxford.

Sveiby, K.E. and Simons, R. 2002, 'Collaborative climate and effectiveness of knowledge work - an empirical study', Journal of Knowledge Management, Vol. 6, pp. 420-433.

Tianyong, W, Zhengliang, X and Gel, G. 2006, 'Development and Strategy of Knowledge Management for E-services', IEEE Xplore

http://books.google.com.au/books?hl=en\&lr=\&id=2iRY4HLtjeIC\&oi=fnd\&pg=PA89\&dq=knowledg $\mathrm{e}+$ management + research\&ots $=$ KA1f3G2iyV\&sig $=$ RR5Kk1IciXU7YmFO7fTiG1O69E $\# \mathrm{v}=$ onepage $\& q=$ knowledge $\% 20$ management $\% 20$ research $\& \mathrm{f}=$ false

http://www.londonmet.ac.uk/depts/cctm/research/knowledge-management-research-centre/phdtopics.cfm 